Bài báo khoa hoc

\title{
Đánh giá tác động của biến đổi khí hậu đến lĩnh vực sử dụng đất và một số giải pháp thích ứng với biến đổi khí hậu tại tỉnh Bình Phước
}

\section{Lê Hoài Nam ${ }^{*}$, Hồ Công Toàn², Nguyễn Văn Tín ${ }^{3}$, Trần Tuấn Hoàng², Phạm Thanh Long $^{2}$}

${ }^{1}$ Trung tâm Quan trắc Môi trường miền Nam; lhnammt@gmail.com;

${ }^{2}$ Phân Viện Khoa học Khí tượng Thủy văn và Biến đổi khí hậu; hocongtoanhdh@gmail.com; hoangkttv@gmail.com; longphamsihymete@gmail.com;

${ }^{3}$ Trường Đại học Tài nguyên và Môi trường TP. HCM; tin.sihymete@gmail.com;

*Tác giả liên hệ: 1hnammt@gmail.com; Tel.: +84-913145914

Ban Biên tập nhận bài: 21/3/2021; Ngày phản biện xong: 21/4/2021; Ngày đăng bài: 25/5/2021

Tóm tắt: Nghiên cứu đưa ra kết quả phân tích, đánh giá tác động của biến đổi khí hậu (BĐKH) đến lĩnh vực sử dụng đất ở tỉnh Bình Phước dựa trên bộ chỉ số đánh giá theo các kết quả mô hình khí hậu, mô hình ngập. Trên cơ sở đó, nghiên cứu đã đưa ra những kết quả về mức độ tác động và đánh giá ảnh hưởng của chúng đến sử dụng đất (SDĐ) ở tỉnh Bình Phước, cụ thể: đất đai thành phố Đồng Xoài (TP. Đồng Xoài) chịu mức độ tác động thấp nhất từ $0,54-0,55$; huyện Bù Đốp chịu tác động do BĐKH đến lĩnh vực sử dụng đất ở mức cao, với chỉ số tác động từ $0,60-0,66$ theo một số kịch bản. Những huyện thị khác của tỉnh Bình Phước có phạm vi SDĐ bị tác động vừa tới mức cao với chỉ số tác động từ $0,54-0,60$. Đồng thời, bài báo đề xuất một số giải pháp thích ứng với $\mathrm{BĐKH}$, những kết quả nghiên cứu này sẽ góp phần cung cấp thông tin cho tỉnh Bình Phước, phục vụ quy hoạch lại SDĐ một cách hợp lý trong bối cảnh BĐKH.

Từ khóa: Mức độ tác động; Biến đổi khí hậu; Sử dụng đất, Thích ứng.

\section{Mở đầu}

Biến đổi khí hậu trong giai đoạn hiện tại là do các hoạt động công nghiệp, xã hội làm phát thải quá mức các khí nhà kính vào bầu khí quyển [1]. Rất nhiều nghiên cứu về BĐKH đã được triển khai theo 3 hướng chính đó là [2]: (i) Nghiên cứu bản chất, nguyên nhân, cơ chế vật lý của BĐKH [1-3]; (ii) Đánh giá tác động của BĐKH, tính dễ bị tổn thương (DBTT) do $\mathrm{BĐKH} \mathrm{[4-8];} \mathrm{(iii)} \mathrm{Giải} \mathrm{pháp} \mathrm{chiến} \mathrm{lược} \mathrm{và} \mathrm{kế} \mathrm{hoạch} \mathrm{hành} \mathrm{động} \mathrm{nhằm} \mathrm{giảm} \mathrm{thiểu} \mathrm{B} Đ K H$ [9-11].

Đánh giá tác động do $\mathrm{BĐKH} \mathrm{là} \mathrm{nghiên} \mathrm{cứu} \mathrm{xác} \mathrm{định} \mathrm{các} \mathrm{ảnh} \mathrm{hưởng} \mathrm{của} \mathrm{BĐKH} \mathrm{lên} \mathrm{môi}$ trường và các hoạt động kinh tế xã hội của địa phương. Ngoài ảnh hưởng bất lợi, BĐKH còn có thể mang lại những ảnh hưởng có lợi. Đánh giá tác động của BĐKH cũng bao gồm việc xác định và đánh giá các giải pháp thích ứng với $\mathrm{B} Đ K H$ [4]. Hiện nay có nhiều cách tiếp cận trong đánh giá tác động của BĐKH. Theo IPCC, có 3 cách: Tiếp cận tác động (impactapproach), tiếp cận tương tác (interaction-approach) và tiếp cận tổng hợp (integratedapproach). Mỗi cách tiếp cận có những điểm mạnh và hạn chế riêng, theo đó, tùy thuộc vào nhiều yếu tố khác nhau (yêu cầu đánh giá, phạm vi, khung thời gian và nguồn lực...) để lựa chọn [4]. BĐKH với những biểu hiện như nóng lên toàn cầu, biến đổi lượng mưa, nước biển dâng, các hiện tượng thời tiết cực đoan sẽ tác động đến hầu hết mọi lĩnh vực như nông nghiệp, 
công nghiệp, du lịch hay tài nguyên đất, tài nguyên nước và đến cả đời sống con người [1]. Trong đó tài nguyên đất với lĩnh vực quan trọng là $\mathrm{SD}$, một trong những đối tượng chịu tác động mạnh mẽ của $B Đ K H$ và các vấn đề ngập úng, hạn hán, sa mạc hóa, xói mòn, sạt lở, ... ngày càng nặng nề sẽ ảnh hưởng trực tiếp đến sự phát triển kinh tế-xã hội. Đã có không ít các nghiên cứu về đánh giá tác động của $\mathrm{B} Đ K H$ và đề xuất giải pháp thích ứng liên quan đến vấn đề SDĐ, tài nguyên đất ở Việt Nam như: Năm 2019, Tuân và cộng sự [13] đã thực hiện nghiên cứu tác động của $\mathrm{BĐKH}$ đến nông nghiệp và sáng kiến thích ứng với $\mathrm{B} Đ K H$ tại huyện Văn Bản, tỉnh Lào Cai [13]; Năm 2018, Ngọc và cộng sự [14] đã đánh giá các loại hình sử dụng đất nông nghiệp thích ứng với BĐKH ở huyện Quảng Điền, tỉnh Thừa Thiên Huế. Trong khi đó, Vũ và cộng sự [15] đã đánh giá tác động của mặn và ngập theo kịch bản $\mathrm{BĐKH}$ đến tiềm năng thích nghi đất đai vùng ven biển đồng bằng sông Cửu Long hay nghiên cứu bố trí SDĐ của tỉnh Nam Định để thích ứng với BĐKH [16].

Nằm ở vùng Đông Nam Bộ, tỉnh Bình Phước được dự báo đến giữa thế kỷ nhiệt độ tăng $1,40^{\circ} \mathrm{C}$, lượng mưa năm có mức biến đổi từ 9,20-9,90\% [12]; Vào cuối thế kỷ, mức tăng nhiệt độ được dự báo khoảng $1,90^{\circ} \mathrm{C}$, đối với lượng mưa mức biển đổi khoảng 14,50-16,60\% theo kịch bản phát thải trung bình (RCP4.5) [12]. BĐKH những thay đổi về hình thái trong chu trình nước: mưa-nước bốc hơi... đều dẫn đến sự thay đổi cơ chế ẩm trong đất, lượng nước ngầm và các dòng chảy. Nguy cơ nóng và đất đai khô cằn sẽ dẫn đến gia tăng diện tích đất bị thoái hóa ở Bình Phước. Ngược lại, việc sử dụng đất đai cũng có ảnh hưởng đối với sự thay đổi các yếu tố khí hậu. Lượng phát thải khí nhà kính do sử dụng đất, chặt phá dẫn đến suy thoái rừng... là những nguyên nhân tác động đến sự nóng lên của toàn cầu. Ngập gây ảnh hưởng đến kết cấu đất đai, chất lượng tài nguyên đất và nhu cầu sử dụng đất ở các khu vực xảy ra hiện tượng này. Ngập do lũ ảnh hưởng đến các loại đất như: đất rừng, đất trồng cây công nghiệp, đất sông hồ, đất giao thông tập trung ở các huyện Bù Gia Mập, Bù Đăng, Bù Đốp và một phần thị xã Phước Long.

Trước các sức ép về tốc độ phát triển kinh tế-xã hội trên địa bàn tỉnh Bình Phước kết hợp những biến đổi của khí hậu đang ngày càng nghiêm trọng thì nghiên cứu đánh giá tác động của $\mathrm{B} Đ K H$ đến lĩnh vực $\mathrm{SDĐ}$ và đề xuất một số giải pháp thích ứng được tiến hành. Nhóm tác giả đã sử dụng phương pháp bộ chỉ số đánh giá dựa trên những kết quả kịch bản của mô hình khí hậu và mô hình ngập. Với mục tiêu đánh giác tác động của $\mathrm{BĐKH} \mathrm{đến} \mathrm{lĩnh}$ vực SDĐ theo các cấp thang đo trong bộ chỉ số cho tỉnh Bình Phước.

\section{Phương pháp nghiên cứu}

\subsection{Giới thiệu khu vục nghiên cứu}

Nghiên cứu được thực hiện trên khu vực tỉnh Bình Phước, là một tỉnh thuộc miền Đông Nam Bộ, có đường biên giới tiếp giáp với Campuchia dài 260,433 km (Hình 1). Khu vực nghiên cứu có địa bàn trung chuyển giữa Nam Tây Nguyên và miền Đông Nam Bộ, nên tỉnh có địa hình rất đa dạng, gồm cả địa hình cao nguyên, đồi núi và đồng bằng. Nằm trong vùng kinh tế trọng điểm phía Nam, có vị trí không xa Thành phố Hồ Chí Minh-trung tâm kinh tế lớn nhất của cả nước-lại có cửa khẩu thông thương với Campuchia, Bình Phước có rất nhiều cơ hội để phát triển thương mại, du lịch và xuất khẩu, ... Bình Phước có địa hình tương đối bằng phẳng hơn so với các tỉnh miền núi khác trong cả nước. Đất có độ dốc trên 250 chỉ chiếm $11,27 \%$ diện tích tự nhiên (DTTN) của tỉnh. Đất có chất lượng trung bình trở lên chiếm $74,43 \%$ DTTN, trong đó đất có chất lượng cao nhất chiếm $60,69 \%$ tổng DTTN. Theo Niên giám thống kê tỉnh Bình Phước năm 2016, toàn tỉnh có 6 nhóm đất chính gồm: nhóm đất xói mòn, trơ sỏi đá (chiếm 0,03\%), nhóm đất đen (chiếm 0,09\%), nhóm đất dốc tụ (chiếm 3,50\%) nhóm đất phù sa (chiếm $0,13 \%$ ), nhóm đất xám (chiếm $13,61 \%$ ) và nhóm đất nâu, đỏ vàng (chiếm 78,55\%) trong cơ cấu nhóm đất của Tỉnh. Trong cơ cấu SDĐ thì đất rừng đặc dụng, rừng phòng hộ tự nhiên có diện tích nhiều nhất. 


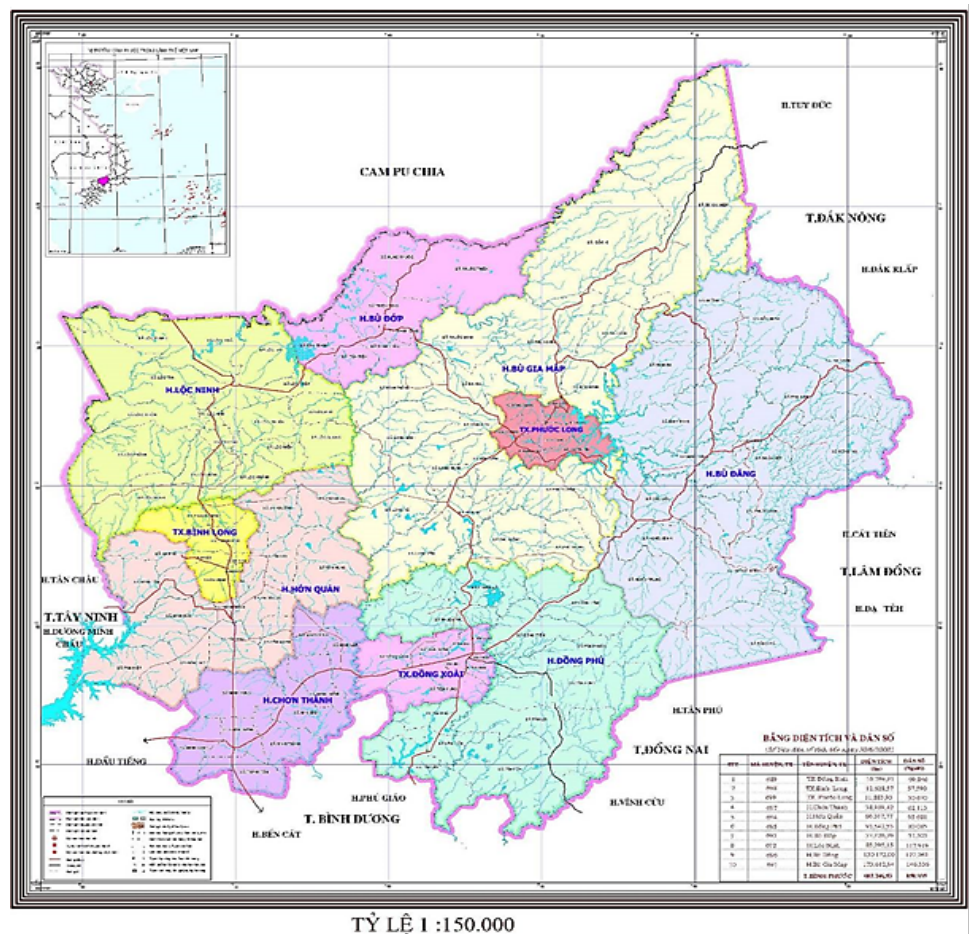

Hình 1. Bản đồ hành chính tỉnh Bình Phước.

\subsection{Phương pháp đánh giá tác động của BĐKH bằng chỉ số (kết hợp GIS)}

Chỉ số những tác động của BĐKH được xác lập trong mối quan hệ của 03 yếu tố (Hình 2): mức độ phơi nhiễm (E), mức độ nhạy cảm (S) [4,10]. Các thuật ngữ này có thể thay đổi trong các nghiên cứu khác nhau.

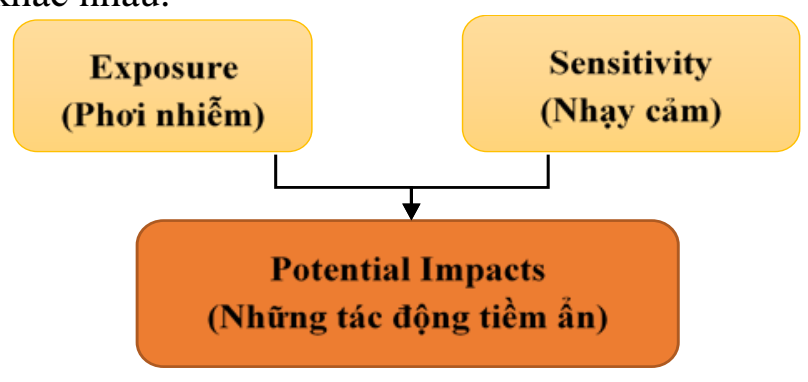

Hình 2. Mô hình ý niệm đánh giá tính DBTT do BĐKH [4].

Áp dụng phương pháp chỉ số để đánh giá tác động tiềm ẩn và tính dễ bị tổn thương (DBTT) đối với biến đồi khí hậu theo quy trình như sau:

Bước 1: Xác định bộ chỉ thị (BCT)

BCT và trọng số tương ứng phục vụ đánh giá tác động của BĐKH bao gồm các chỉ thị thể hiện khả năng phơi nhiễm $\mathrm{E}$, tính nhạy cảm $\mathrm{S}$ (từ đó đánh giá được tác động $\mathrm{I}$ ). Phương pháp tổng quan tài liệu và tham vấn chuyên gia cũng đồng thời được sử dụng ở nội dung này.

Căn cứ vai trò của các chỉ thị trong mỗi nhóm, các trọng số được xác định như sau:

+ Khả năng phơi nhiễm được đánh giá thông qua các tác nhân/hiện tượng với trọng số không giống nhau. Trên cơ sở đặc điểm của mỗi tác nhân trong mối quan hệ (tác động) trực tiếp đối với BĐKH cùng với ý kiến của các chuyên gia, trọng số của các tác nhân được xác định (gọi là trọng số tác nhân). Tương tự đối với tính nhạy cảm và khả năng thích ứng, lần lượt xác định được trọng số đặc điểm và trọng số nguồn lực.

+ Trọng số của các chỉ thị thành phần trong cùng một nhóm (khía cạnh) được xác định dựa trên vai trò đối với khía cạnh mà chúng đại diện (gọi là trọng số riêng). 
+ Trọng số của từng chỉ thị xét trong cả bộ chỉ thị được tính bằng tích số giữa trọng số riêng và trọng số tác nhân/đặc điểm/nguồn lực (gọi là trọng số uu tiên).

Bước 2: Chuẩn hóa các số liệu thực (chỉ thị) theo thang điểm 0-1

Các chỉ thị có đơn vị và tỷ lệ khác nhau, vì thế cần chuẩn bằng cách đồng nhất giá trị từ $0-1$.

- Đối với các chỉ thị tỉ lệ (\%): nếu tỉ lệ được xét trong cùng một hệ thống (toàn vùng nghiên cứu), chỉ thị được chuẩn hoá bằng cách giữ nguyên giá trị và bỏ đơn vị \%.

- Đối với hầu hết các chỉ thị $\mathrm{E}$ (như nhiệt độ, lượng mưa, bão), $\mathrm{S}$ và $\mathrm{AC}$ : chuẩn hóa theo công thức sau:

+ Quan hệ thuận với cấu phần đang xét:

$$
\text { Chỉ số }=\frac{\text { (Giá trị thực }- \text { Giá trị nhỏ nhất) }}{\text { (Giá trị lớn nhất }- \text { Giá trị nhỏ nhất) }}
$$

+ Quan hệ nghịch với cấu phần đang xét:

$$
\text { Chî số }=\frac{\text { (Giá trị lớn nhất }- \text { Giá trị thực) }}{\text { (Giá trị lớn nhất }- \text { Giá trị nhỏ nhất) }}
$$

Bước 3: Tính toán chỉ số tổng hợp

Chỉ số tổng hợp của từng cấu phần $(\mathrm{E}, \mathrm{S})$ được tính toán dựa trên giá trị chuẩn hoá của chỉ thị i và trọng số ưu tiên wi theo các công thức dưới đây. Chỉ số I là hàm số của nhóm chỉ số E và $S$.

$$
\begin{gathered}
E=\sum_{i=1}^{n} E_{i} * \mathrm{WE}_{i} \quad(3) \quad S=\sum_{i=1}^{n} S_{i} * W S_{i} \\
\mathrm{I}=\mathrm{E} * \mathrm{~S}
\end{gathered}
$$

Trong đó I là tác động của thiên tai; $\mathrm{E}$ là nguy cơ hứng chịu thiên tai; $\mathrm{S}$ mức độ nhạy cảm với nguy cơ thiên tai; $\mathrm{E}_{\mathrm{i}}, \mathrm{S}_{\mathrm{i}}$ lần lượt là giá trị chuẩn hoá của chỉ thị thứ i trong cấu phần $\mathrm{E}, \mathrm{S}$; WEi, WSi lần lượt là trọng số ưu tiên của chỉ thị thứ i trong cấu phần $\mathrm{E}, \mathrm{S}$; n là số lượng các chỉ thị thành phần (của mỗi cấu phần $\mathrm{E}, \mathrm{S}, \mathrm{AC}$ ).

Sự tác động của thiên tai được xác định là: $\mathrm{I}=\mathrm{E} * \mathrm{~S}$.

Tác động của $\mathrm{BĐKH} \mathrm{thông} \mathrm{qua} \mathrm{sự} \mathrm{gia} \mathrm{tăng} \mathrm{các} \mathrm{loại} \mathrm{hình} \mathrm{thiên} \mathrm{tai} \mathrm{là} \mathrm{bão,} \mathrm{xâm} \mathrm{nhập} \mathrm{mặn,}$ mưa lớn, ngập lụt, nắng nóng và hạn hán kết hợp với mức độ nhạy cảm thiên tai;

Mức độ hứng chịu thiên tai tại một vùng là lớn và mức độ nhạy cảm với thiên tai cũng lớn $\rightarrow$ tác động mạnh;

Ngược lại, một vùng hứng chịu nhiều thiên tai, nhưng các yếu tố như dân cư, sản xuất nông nghiệp, cơ sở hạ tầng... ít hay hoặc không có $\rightarrow$ ít bị tác động;

Hoặc, nhạy cảm với thiên tai cao, nhưng thiên tai ít xảy ra thiên tai không xảy ra hoặc xảy ra rất ít và nhẹ $\rightarrow$ ít tác động;

Sự tác động của thiên tai được xác định là sự kết hợp của mức độ hứng chịu thiên tai với mức độ nhạy cảm với thiên tai.

Tác động được diễn tả: $\mathrm{I}=\mathrm{E} * \mathrm{~S}$

+ I: tác động của thiên tai;

+ E: nguy cơ hứng chịu thiên tai;

+ S: các tổn thất đối với thiên tai (mức độ nhạy cảm với nguy cơ thiên tai).

+ Chỉ số dễ bị tổn thương diễn tả mức độ tác động được làm giảm đi nhờ vào khả năng ứng phó tốt hay thích ứng cao với những tác động của thiên tai;

+ Tác động của BĐKH mạnh, thích ứng - ứng phó tốt $\rightarrow$ tổn thương thấp;

+ Ngược lại, tác động của BĐKH nhỏ, nhưng địa phương không ứng phó hoặc thích ứng kém $\rightarrow$ bị tổn thương rất cao.

Bước 4: Thành lập bộ chỉ số và đánh giá 
Bảng 1. Bộ chỉ thị nguy cơ hứng chịu thiên tai (E) trên địa bàn tỉnh Bình Phước.

\begin{tabular}{|c|c|c|c|}
\hline Hiện tưọng (1) & Chỉ thị (2) & Ký hiệu & Quan hệ \\
\hline Nhiệt độ & $\begin{array}{l}\text { Mức độ gia tăng nhiệt độ tối cao so với giai } \\
\text { đoạn } 1986-2005\left({ }^{\circ} \mathrm{C}\right)\end{array}$ & E.1.1 & + \\
\hline Lượng mưa & $\begin{array}{l}\text { Mức độ gia tăng lượng mưa năm so với giai } \\
\text { đoạn } 1986 \text { - } 2005 \text { (\%) }\end{array}$ & E.1.2 & + \\
\hline Bão, ATNĐ, & $\begin{array}{l}\text { Số lượng cơn bão, áp thấp nhiệt đới, gây ảnh } \\
\text { hưởng trong } 10 \text { năm (cơn) }\end{array}$ & E.1.3 & + \\
\hline Hạn hán & $\begin{array}{l}\text { Chỉ số khô hạn và mức độ biến đổi trong } 20 \\
\text { năm }\end{array}$ & E.1.6 & + \\
\hline \multirow[t]{2}{*}{ Ngập lũ } & Phạm vi ngập lớn nhất (>0.1m) (ha) & E.1.7 & + \\
\hline & Độ sâu ngập lớn nhất (m) & E.1.8 & + \\
\hline
\end{tabular}

Bảng 2. Bộ chỉ thị mức độ nhạy cảm với nguy cơ thiên tai $(\mathrm{S})$ trên địa bàn tỉnh Bình Phước.

\begin{tabular}{|c|c|c|c|}
\hline Khía cạnh (1) & Chỉ thị (2) & Ký hiệu & Mối quan hệ \\
\hline \multirow{3}{*}{$\begin{array}{l}\text { Tài nguyên } \\
\text { rừng }\end{array}$} & Diện tích rừng phòng hộ (ha) & S.1.1.1 & - \\
\hline & Diện tích rừng đặc dụng (ha) & S.1.1.2 & - \\
\hline & Diện tích rừng sản xuất (ha) & S.1.1.3 & - \\
\hline \multirow[t]{4}{*}{ Sử dụng đất } & $\begin{array}{l}\text { Đất sản xuất nông nghiệp: Đất trồng cây hàng năm, đất trồng lúa, } \\
\text { đất cỏ dùng vào chăn nuôi, đất trồng cây hàng năm khác (ha) }\end{array}$ & S.1.2.1 & + \\
\hline & $\begin{array}{l}\text { Đất lâm nghiệp: có rừng (rừng sản xuất rừng phòng hộ, rừng đặc } \\
\text { dụng) (ha) }\end{array}$ & S.1.2.2 & - \\
\hline & $\begin{array}{l}\text { Đất chuyên dùng: Đất trụ sở cơ quan, công trình sự nghiệp, đất } \\
\text { quốc phòng - an ninh, đất sản xuất, kinh doanh phi nông nghiệp, } \\
\text { đất có mục đích công cộng (ha) }\end{array}$ & S.1.2.3 & + \\
\hline & Đất ở: Đất ở đô thị, đất ở nông thôn (ha) & S.1.2.4 & + \\
\hline $\begin{array}{l}\text { Tài nguyên } \\
\text { khoáng sản }\end{array}$ & Tổng diện tích khoáng sản theo từng huyện/thị (ha) & S.1.3.1 & - \\
\hline \multirow{3}{*}{$\begin{array}{l}\text { Tài nguyên } \\
\text { nước }\end{array}$} & Nhu cầu sử dụng nước dưới đất (m³/ngày) & S.1.4.1 & - \\
\hline & Nhu cầu sử dụng nước sinh hoạt tại các vùng đô thị (m³/ngày) & S.1.4.2 & - \\
\hline & $\begin{array}{l}\text { Nhu cầu sử dụng nước sinh hoạt tại các vùng nông thôn } \\
\text { (m³/ngày) }\end{array}$ & S.1.4.3 & - \\
\hline
\end{tabular}

\subsection{Phưong pháp lập bản đồ}

Các bản đồ phân bố SDĐ và bản đồ chỉ số tác động đề tài được xây dựng bằng kỹ thuật tích hợp thông tin, chồng ghép các lớp thông tin có trọng số, tổng hợp, tính toán cho các chỉ số chính và chỉ số phụ... thông qua phần mềm ArcGIS 10.1 trên bản đồ nền tỷ lệ 1: 50.000, hệ tọa độ VN 2000.

\subsection{Số liệu}

Các tài liệu, số liệu liên quan đến hiện trạng và quy hoạch $\mathrm{SDĐ}$, tình hình $\mathrm{BĐKH,} \mathrm{số}$ liệu hành chính được thu thập và phân tích. Bên cạnh đó, kết quả tính toán kịch bản nhiệt độ, lượng mưa [12], nguy cơ ngập, dữ liệu bão được kế thừa từ đề tài "Đánh giá ảnh hưởng của BĐKH đến biến động diện tích và cơ cấu sử dụng đất, tiềm năng phát triển kinh tế xã hội, 
tiềm năng khai thác các loại tài nguyên khoáng sản trên địa bàn tỉnh Bình Phước” [12] làm cơ sở để xây dựng bản đồ tác động khoanh vùng các khu vực đáng quan tâm, phục vụ phân tích, đánh giá và đề xuất một số giải pháp thích ứng.
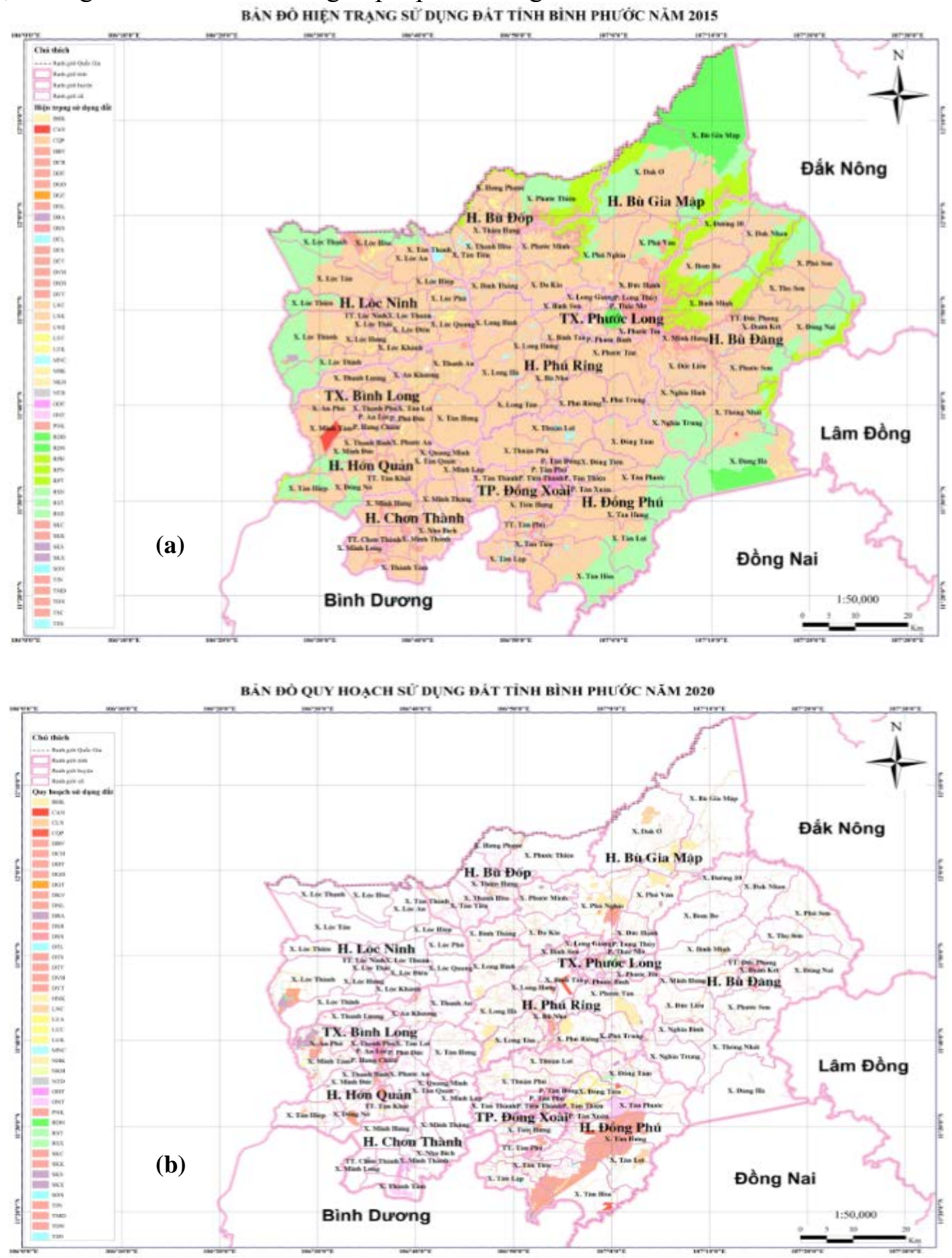

Hình 4. Bản đồ hiện trạng SDĐ năm 2015 (a) và quy hoạch SDĐ đến năm 2020 (b) tỉnh Bình Phước.

\section{Kết quả và thảo luận}

\section{1 Đánh giá tác động của BĐKH đến sư dụng đất tỉnh Bình Phước}

Dựa trên bản đồ hiện trạng SDĐ năm 2015 và quy hoạch SDĐ đến năm 2020 kết hợp với bộ chỉ số hứng chịu $(\mathrm{E})$ và bộ chỉ số nhạy cảm $(\mathrm{S})$ trình bày ở mục 2.2 trong Bảng 1 và Bảng 2. Từ đó nhóm nghiên cứu thực hiện tính toán dự báo mức độ tác động của $\mathrm{B} Đ K H$ đến lĩnh vực SDĐ tỉnh Bình Phước (Bảng 3). 
Bảng 3. Kết quả tính toán chỉ số tác động của BĐKH đến SDĐ tỉnh Bình Phước.

\begin{tabular}{|c|c|c|c|c|c|c|c|c|c|c|}
\hline $\begin{array}{l}\text { Huyện } \\
\text { thành }\end{array}$ & $\begin{array}{l}\text { Chỉ } \\
\text { số E }\end{array}$ & $\begin{array}{c}\text { Chỉ } \\
\text { số } \mathrm{S}\end{array}$ & $\begin{array}{l}\text { I 45- } \\
2025\end{array}$ & $\begin{array}{l}\text { I 45- } \\
2030\end{array}$ & $\begin{array}{l}\text { I 45- } \\
2050\end{array}$ & $\begin{array}{l}\text { I 45- } \\
2100\end{array}$ & $\begin{array}{l}\text { I 85- } \\
2025\end{array}$ & $\begin{array}{l}\text { I 85- } \\
2030\end{array}$ & $\begin{array}{l}\text { I 85- } \\
2050\end{array}$ & $\begin{array}{l}\text { I 85- } \\
2100\end{array}$ \\
\hline Đồng & 0,33 & 0,21 & 0,54 & 0,55 & 0,54 & 0,55 & 0,55 & 0,55 & 0,56 & 0,56 \\
\hline \multicolumn{11}{|l|}{ Xoài } \\
\hline Phước & 0,37 & 0,24 & 0,60 & 0,63 & 0,62 & 0,64 & 0,58 & 0,59 & 0,64 & 0,64 \\
\hline \multicolumn{11}{|l|}{ Long } \\
\hline Bình & 0,37 & 0,24 & 0,61 & 0,60 & 0,60 & 0,61 & 0,61 & 0,59 & 0,60 & 0,59 \\
\hline \multicolumn{11}{|l|}{ Long } \\
\hline Chơn & 0,35 & 0,25 & 0,60 & 0,60 & 0,60 & 0,60 & 0,60 & 0,60 & 0,60 & 0,59 \\
\hline \multicolumn{11}{|l|}{ Thành } \\
\hline Hớn & 0,37 & 0,25 & 0,62 & 0,61 & 0,60 & 0,61 & 0,62 & 0,61 & 0,60 & 0,59 \\
\hline \multicolumn{11}{|l|}{ Quản } \\
\hline Đồng & 0,32 & 0,26 & 0,58 & 0,61 & 0,59 & 0,60 & 0,59 & 0,62 & 0,60 & 0,61 \\
\hline \multicolumn{11}{|l|}{ Phú } \\
\hline Lộc Ninh & 0,38 & 0,19 & 0,57 & 0,56 & 0,56 & 0,57 & 0,55 & 0,55 & 0,56 & 0,55 \\
\hline Phú & 0,36 & 0,25 & 0,61 & 0,63 & 0,62 & 0,64 & 0,59 & 0,60 & 0,62 & 0,61 \\
\hline \multicolumn{11}{|l|}{ Riềng } \\
\hline Bù Đăng & 0,36 & 0,21 & 0,57 & 0,57 & 0,57 & 0,57 & 0,58 & 0,56 & 0,58 & 0,59 \\
\hline Bù Đốp & 0,41 & 0,23 & 0,64 & 0,63 & 0,64 & 0,66 & 0,62 & 0,61 & 0,65 & 0,63 \\
\hline Bù Gia & 0,43 & 0,17 & 0,60 & 0,61 & 0,59 & 0,60 & 0,56 & 0,57 & 0,61 & 0,59 \\
\hline Mập & & & & & & & & & & \\
\hline
\end{tabular}

Kết quả chỉ số tác động (I) trình bày trong Bảng 3 cho thấy, mức độ tác động do BĐKH đến lĩnh vực $\mathrm{SD}$ là ở mức vừa và cao, cao nhất là 0,66 , dao động từ $0,54-0,60$, tức là ở thang thứ 3 (màu cam) và thứ 4 (màu đỏ) trong thang mức độ tác động. Cụ thể:

- Theo kịch bản RCP4.5:

+ Vào năm 2025 (Hình 5a): Các huyện Bù Đốp, Hớn Quản chịu sự tác động cao nhất và kế đến là huyện Bù Gia Mập, TX. Phước Long, Bình Long, huyện Phú Riềng và Chơn Thành với mức tác động (I) đều trên 0,62 . Đây là những huyện thị xã chịu sự phơi nhiễm từng yếu tố như ngập, mưa, nhiệt độ lớn, hay chịu sự phơi nhiễm của cả ba yếu tố lớn. Bên cạnh đó, những huyện thị này, các loại đất nhạy cảm với thiên tai chiếm phần lớn như: đất rừng, đất nông nghiệp, đất trồng cây công nghiệp, đất nương rẫy, đất sông hồ, đất xử lý rác thải, đất các công trình năng lượng. Trong khi đó, TP. Đồng Xoài chịu sự tác động thấp nhất trong các huyện thành, tuy nhiên theo thang đánh giá tác động (I) thì vẫn ở mức tác động vừa, bằng 0,54 .

+ Vào năm 2030 (Hình 5b): mức độ tác động cao do BĐKH đến sử dụng đất tỉnh Bình Phước đã mở rộng thêm huyện Đồng Phú với chỉ số tác động là 0,61 , huyện Phú Riềng, Bù Đốp và TX. Phước Long chịu sự tác động của $B Đ K H$ cao nhất, chỉ số I là 0,63 . Các huyện Bù Đăng, Lộc Ninh chịu mức độ tác động vừa 0,57 và $T P$. Đồng Xoài chịu mức độ tác động do $\mathrm{BĐKH}$ thấp nhất là 0,55 . Tương tự, vào năm 2050 (Hình $5 \mathrm{c}$ ), chỉ số tác động giống với năm 2030

+ Đến cuối thế kỷ (năm 2100): mức độ tác động do BĐKH đối với cơ cấu sử dụng đất ở hầu hết các huyện, thị như Bình Long, Hớn Quản, Đồng Phú, Bù Gia Mập, Chơn Thành là không đổi. Các huyện Bù Đốp, TX. Phước Long và huyện Phú Riềng, chịu sự tác động rất đáng quan tâm ở tất cả kịch bản, với chỉ số tác động cao nhất là 0,66 . TP. Đồng Xoài chịu mức độ tác động thấp nhất (Hình $5 d$ ). 
+ Ở kịch bản này, khu vực Bắc, trung tâm và Tây Nam của Tỉnh chịu tác động của BĐKH cao hơn so với các khu vực khác, trong đó có huyện Bù Đốp, Hớn Quản, Phú Riềng và TX. Phước Long.
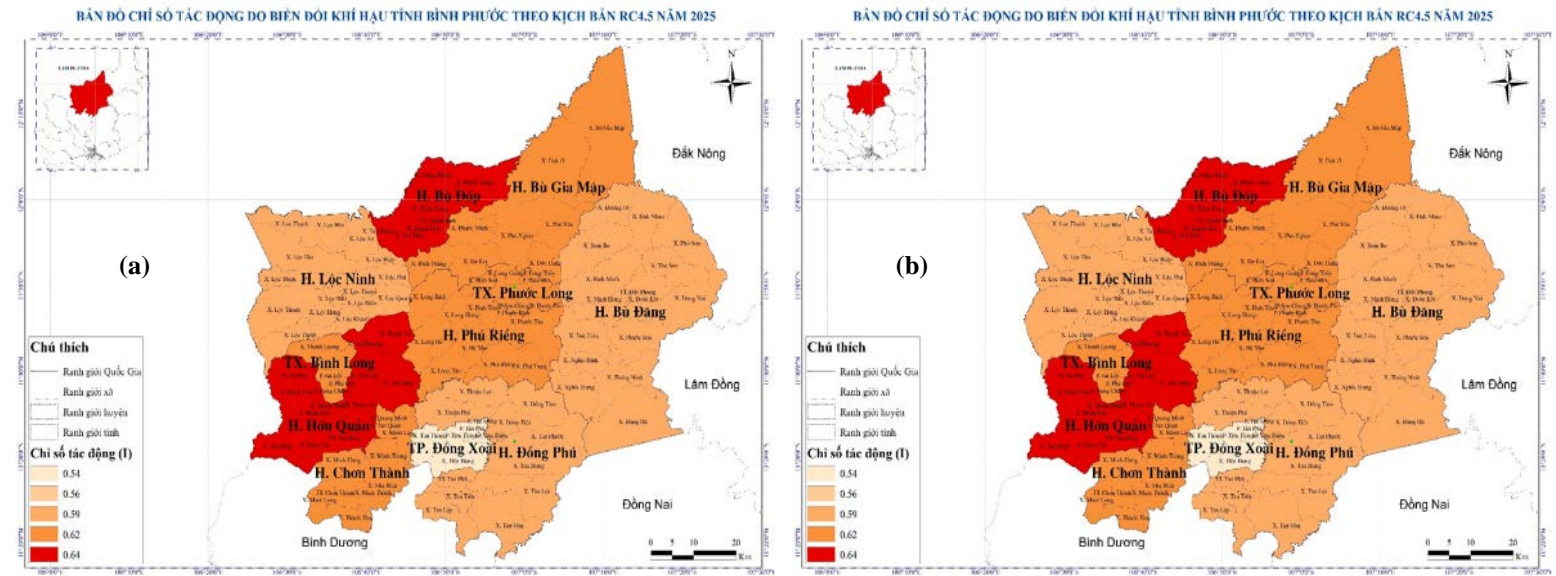

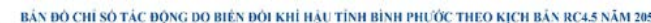

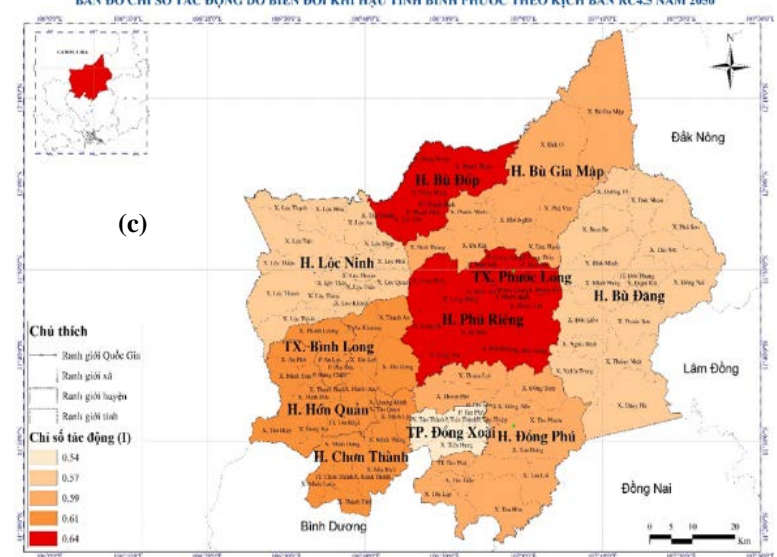

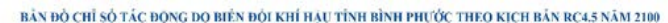

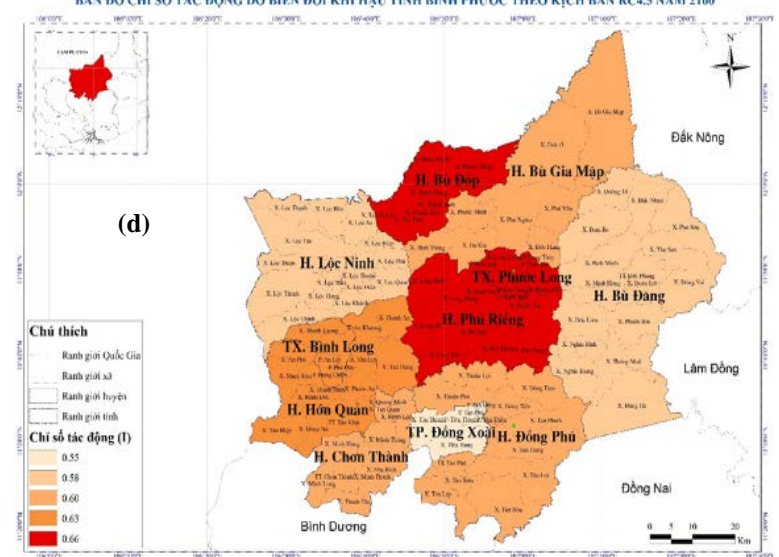

Hình 5. Bản đồ chỉ số tác động do BĐKH đến SDĐ tỉnh Bình Phước theo kịch bản RCP4.5: (a) Năm 2025; (b) Năm 2030; (c) Năm 2050; (d) Năm 2100.

- Theo từng kịch bản RCP8.5:

+ Vào năm 2025 và năm 2030 (Hình 6a, 6b), chỉ số I ở mức từ 0,55-0,62, chênh lệch giữa hai mốc thời gian là không nhiều. Tuy nhiên các khu vực khai thác khoáng sản bị tác động cao đã thay đổi, Đồng Phú ở giữa thế kỷ chịu mức tác động vừa. Vào năm 2050 , chỉ số tác động ở mức cao nhất tới 0,602 , dao dộng trong khoảng từ $0,37-0,60.4 / 11$ huyện thị ở mức vừa là Bù Gia Mập, Bù Đốp, Phú Riềng, Hớn Quản. Khu vực không thay đổi nhiều so với năm 2025 và 2030 nhưng mức tác động cao hơn.

+ Đến năm 2050 (Hình 6c), phạm vi tác động thay đổi, và mức độ tác động từ 0,56-0,65. Có 8/11 huyện thị chịu mức độ tác động cao là Phước Long, Bình Long, Chơn Thành, Bù Đốp, Phú Riềng, Hớn Quản. Đồng Phú, Bù Đốp và Bù Gia Mập, với chỉ số tác động từ 0,60 0,62 , cao nhất là 0,65 tác động lên huyện Bù Đốp.

+ Đến cuối thế kỷ (năm 2100): mức độ tác động do BĐKH đối với cơ cấu sử dụng đất ở hầu hết các huyện, thị như Bình Long, Hớn Quản, Đồng Phú, Bù Gia Mập, Chơn Thành là không đổi. Các huyện Bù Đốp, TX. Phước Long và huyện Phú Riềng, chịu sự tác động rất đáng quan tâm, với chỉ số tác động cao nhất là 0,63 . TP. Đồng Xoài chịu mức độ tác động thấp nhất. Đồng thời ở kịch bản này phạm vi tác động cao do BĐKH bị thu hẹp hơn so với ở kịch bản năm 2025 và năm 2030. Còn so với kịch bản RCP4.5 năm 2100 thì chỉ tác động ở kịch bản này nhỏ hơn nhưng không đáng kể (Hình $6 \mathrm{~d}$ ).

+ Đối với kịch bản RCP8.5, khu vực phía Bắc, trung tâm, Nam và Tây Nam của Tỉnh chịu tác động của $\mathrm{B} Đ K H$ cao hơn so với các khu vực khác. Phạm vi chịu tác động $\mathrm{B} Đ K H$ 
mở rộng hơn so với kịch bản RCP4.5, trong đó có huyện Chơn Thành, Đồng Phú, Bù Đốp, Hớn Quản, Phú Riềng và TX. Phước Long.
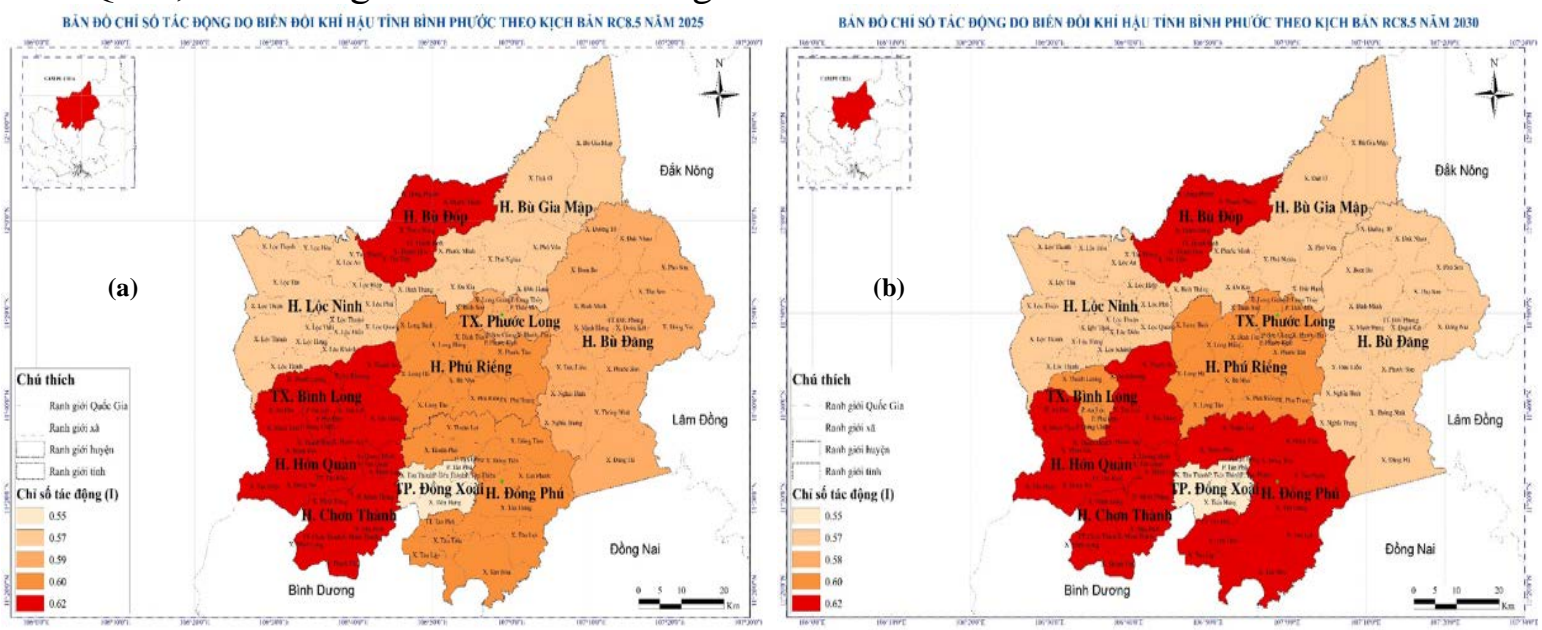

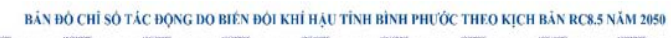

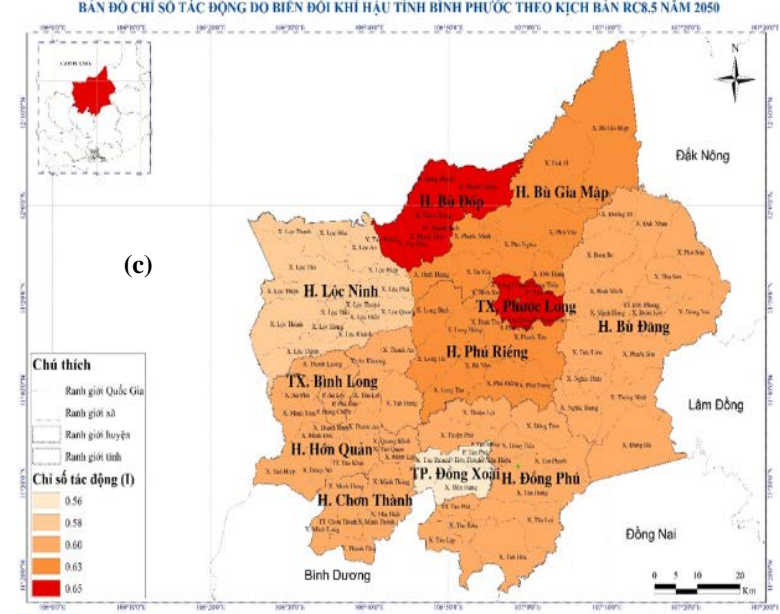

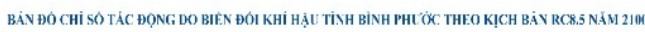

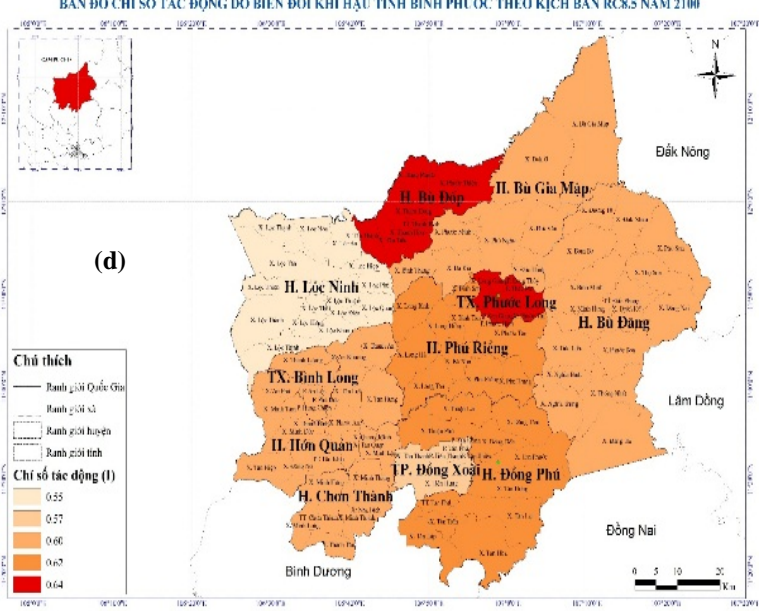

Hình 6. Bản đồ chỉ số tác động do BĐKH đến SDĐ tỉnh Bình Phước theo kịch bản RCP8.5: (a) Năm 2025; (b) Năm 2030; (c) Năm 2050; (d) Năm 2100.

\subsection{Một số giải pháp thích ứng với BĐKH liên quan đến sử dụng đất tỉnh Bình Phuớc}

Giải pháp chính sách: Tích hợp yếu tố BĐKH vào các chiến lược, quy hoạch và kế hoạch sử dụng đất: là hoạt động rà soát, điều chỉnh, bổ sung cho các chiến lược, quy hoạch và kế hoạch đó, bao gồm chủ trương, chính sách, cơ chế, tổ chức có liên quan đến việc thực hiện chiến lược, quy hoạch và kế hoạch, các nhiệm vụ và sản phẩm cũng như các phương tiện, điều kiện thực hiện cho phù hợp với xu thế BĐKH, các hiện tượng khí hậu cực đoan và những tác động trước mắt và lâu dài của chúng đối với tài nguyên đất.

Giải pháp khoa họ công nghệ: Các kết luận khoa học chính là cơ sở cho việc hoạch định các quy hoạch, chiến lược và chính sách về đất đai cho sự phát triển bền vững. Nhà nước cần đầu tư thích đáng cho các chương trình nghiên cứu nhằm giảm nhẹ và thích ứng với những tác động của $\mathrm{BĐKH}$ đến tài nguyên đất, các chương trình nghiên cứu và đánh giá tính tổn thương của các loại hình sử dụng đất.

Giải pháp tuyên truyền: Nâng cao năng lực, giáo dục và truyền thông: Biện pháp quan trọng khác nữa là cần nâng cao nhận thức của cộng đồng, năng lực cho các nhà quản lý, các nhà hoạch định chính sách... về khí hậu và $\mathrm{BĐKH}$ đến tài nguyên đất.

Giải pháp thích ưng:

- Đối với đất đai chịu ảnh hưởng hoặc có nguy cơ chịu ảnh hưởng của $B Đ K H$, việc sử dụng đất sẽ hạn chế và phải được quản lý chặt chẽ. Để làm được điều đó, cần phải đánh giá mức độ bị ảnh hưởng, khả năng chịu ảnh hưởng, tình hình sử dụng đất hiện tại, tính tuần 
hoàn của việc sử dụng đất. Trong đó nên tập trung vào các huyện thị chịu tác động của BĐKH lớn như: Bù Đốp, Chơn Thành, Đồng Phú, Hớn Quản, Phú Riềng và TX. Phước Long. Hay khu vực phía Bắc, trung tâm, Nam và Tây Nam.

- Phải xác định tỉnh Bình Phước nằm ở vùng thường xuyên chịu tác động của những hiện tượng khí hậu như: mưa lớn, lũ, ngập, hạn hán, khô nóng. Hiện tượng này càng có xu hướng xảy ra mạnh mẽ hơn do ảnh hưởng của $\mathrm{BĐKH.} \mathrm{Do} \mathrm{vậy,} \mathrm{định} \mathrm{hướng} \mathrm{sử} \mathrm{dụng} \mathrm{đất} \mathrm{của}$ tỉnh cần chú trọng đẩy mạnh thâm canh ở những nơi có khả năng tưới, tiêu; Tăng cường nông lâm kết hợp, khai thác hợp lý nhất nguồn tài nguyên đất theo hướng sản xuất hàng hóa; Bảo vệ duy trì và phát triển thảm thực vật ở khu vực đầu nguồn, khu vực núi cao, khu vực có tính phòng hộ.

- Bảo vệ, bảo tồn diện tích đất lâm nghiệp hiện có, mở rộng diện tích đất trồng rừng... nhằm thúc đẩy thực hiện các chương trình để bảo tồn và tăng cường bể hấp thụ khí nhà kính.

- Xây dựng chương trình sử dụng có hiệu quả diện tích đất trống, đồi núi trọc tạo việc làm cho người lao động, xóa đói giảm nghèo.

- Rà soát quy hoạch, đặc biệt là các huyện và thị chịu ảnh hưởng mạnh của BĐKH: Uu tiên đất thủy lợi để xây dựng các công trình tiêu úng; Đất giao thông để xây dựng cơ sở hạ tầng phòng chống lụt bão; Đất ở phục vụ cho việc tái định cư, di dân. Quy hoạch sử dụng đất hợp lý tạo điều kiện cho việc định canh, định cư.

\section{Kết luận}

Biến đổi khí hậu ở Bình Phước diễn biến nhanh, dẫn đến diện tích đất bị ngập, khô cằn hay thoái hóa sẽ tăng cao làm ảnh hưởng đến sản xuất kinh tế và đời sống nhân dân.

Bài báo đã đánh giá mức độ tác động của $\mathrm{BĐKH}$ đến sử dụng đất tỉnh Bình Phước:

- Các huyện Bù Gia Mập, Bù Đốp, TX. Phước Long, Phú Riềng, TX. Bình Long, huyện Hớn Quản, Chơn Thành, Đồng Phú chịu sự tác động do BĐKH lớn, đặc biệt là huyện Hớn Quản và TX. Phước Long.

- Qua trình bày tác động do BĐKH đối với tỉnh Bình Phước nhận thấy, các huyện, thị có cơ cấu đất nông nghiệp, đất rừng, đất khoáng sản, đất trồng cây ăn trái, công nghiệp lâu năm, đất sông hồ, đất khu xử lý rác thải chịu sự tác động cao. Còn các loại đất giao thông, công trình, quốc phòng - an ninh, nhà ở, trụ sở ủy ban, công ty chịu sự tác động vừa do BĐKH. Điều trên thể hiện qua kết quả bản đồ chỉ số tác động do biến đổi khí hậu thiết lập dựa trên bản đồ hiện trạng và quy hoạch sử dụng đất, bộ chỉ số nhạy cảm, tổn thất $(\mathrm{S})$ và bộ chỉ số phơi nhiễm, hứng chịu (E).

Tuy nhiên, đất ở tỉnh Bình Phước được sử dụng cho nhiều mục đích khác nhau, trong đó phần lớn đất phục vụ hoạt động nông nghiệp, trồng cây nên dễ chuyển đổi mục đích khác trong cùng lĩnh vực. Nhưng đất rừng, nông nghiệp vẫn có mức độ nhạy cảm với $\mathrm{BĐKH} \mathrm{tăng,}$ khả năng phơi nhiễm của loại đất này với $\mathrm{BĐKH} \mathrm{là} \mathrm{rất} \mathrm{cao.}$

Tuy vậy, BĐKH làm thay đổi nhất định đến cơ cấu và quy hoạch SDĐ, thế nên có thể thử nhiệm nhiều loại cây trồng cho hiệu quả kinh tế cao hơn. Chủ động cải tạo đất đai vào các thời điểm có mưa, đặc biệt là mưa trái mùa. Lượng mưa diễn biến thất thường, do đó có thể chủ động sử dụng đất nông nghiệp vào các hình thức canh tác khác nhau. Nhưng cơ cấu sử dụng đất trong tương lai của tỉnh cũng phải đối mặt nhiều thách thức đó là: Nhiệt độ ngày càng cao, số lượng ngày nắng nóng trên $35^{\circ} \mathrm{C}$ ngày càng nhiều; Ngập tập trung ở các huyện thị ở hồ Thác Mơ và Cần Đơn, nơi có tỷ lệ đất nông nghiệp, rừng khá cao. Lượng mưa mùa mưa ngày càng tăng, đặc biệt đặc biệt là phía Đông của Tỉnh.

Đóng góp của tác giả: Xây dựng ý tưởng nghiên cứu: L.H.N., P.T.L.; Lựa chọn phương pháp nghiên cứu: L.H.N., P.T.L., T.T.H.; Xử lý số liệu: N.V.T., H.C.T.; Tính toán: N.V.T., H.C.T.; Phân tích kết quả: L.H.N., N.V.T., H.C.T.; Viết bản thảo bài báo: L.H.N., N.V.T., H.C.T.; Chỉnh sửa bài báo: H.C.T. 
Lời cảm ơn: Nghiên cứu này được thực hiện dưới sự tài trợ của đề tài nghiên cứu khoa học cấp Tỉnh là đề tài: "Đánh giá ảnh hưởng của $\mathrm{B} Đ K H$ đến biến động diện tích và cơ cấu sử dụng đất, tiềm năng phát triển kinh tế xã hội, tiềm năng khai thác các loại tài nguyên khoáng sản trên địa bàn tỉnh Bình Phước".

Lời cam đoan: Tập thể tác giả cam đoan bài báo này là công trình nghiên cứu của tập thể tác giả, chưa được công bố ở đâu, không được sao chép từ những nghiên cứu trước đây; không có sự tranh chấp lợi ích trong nhóm tác giả.

\section{Tài liệu tham khảo}

1. IPCC. Climate Change 2013: The Physical Science Basis. Contribution of Working Group I to the Fifth Assessment Report of the Intergovernmental Panel on Climate Change. Stocker, T.F.; Qin, D.; Plattner, G.K.; Tignor, M.; Allen, S.K.; Boschung, J.; Nauels, A.; Xia, Y.; Bex, V.; Midgley, P.M. (eds.). Cambridge University Press, Cambridge, United Kingdom and New York, NY, USA, 2013, pp. 1535. https://doi.org/10.1017/CBO9781107415324.

2. Tân, P.V.; Thành, N.Đ. Biến đổi khí hậu ở Việt Nam: Một số kêt quả nghiên cứu, thách thức và cơ hội trong hội nhâp quốc tê. Tạp chi Khoa học ĐHQGHN, Các Khoa học Trái đất và Môi trường 2013, 29, 42-55.

3. Bộ Tài nguyên và Môi trường. Kịch bản Biến đổi khí hậu và nước biển dâng cho Việt Nam. Nhà xuất bản Tài nguyên - Môi trường và Bản đồ Việt Nam, 2016.

4. Viện Khoa học Khí tượng Thủy văn và Môi trường. Hướng dẫn Đánh giá tác động của biến đổi khí hậu và xác định các giải pháp thích ứng. NXB Tài nguyên - Môi trường và Bản đồ Việt Nam, 2011.

5. Nicholls, R.J.; Lowe J.A. Climate Stabilisation and Impacts of Sea-Level Rise. Avoiding Dangerous Climate Change. Cambridge University Press, 2006.

6. Dasgupta, S.; Laplante, B.; Meisner, C.; Wheeler, D.; Yan, J. The Impact of Sea Level Rise on Developing Countries. A Comparative Analysis. World Bank Policy Research Working Paper 4136, 2007.

7. Thủy, T.T.T.; Thăng, V.V.; Quyền, N.H.; Hiệu, N.T.; Hiền, T.D.; Thanh, L.H. Xây dựng bản đồ phân bố cấp độ tác động của biến đổi khí hậu đến quy hoạch, thăm dò, khai thác, chế biến và sử dụng các khoáng sản chủ yếu ở Việt Nam. Tạp chí Khí tương Thủy văn 2020, 720, 23-31.

8. Hậu, N.Q.; Quyên, C.T.; Phong, V.T.; Khoa, L.V.; Minh, V.Q. Đánh giá ảnh hưởng của xâm nhập mặn và các yếu tố kinh tế - xã hội đến sản xuất nông nghiệp huyện Vũng Liêm - tỉnh Vĩnh Long. Tạp chí Khoa học Truoòng Đại học Cần Tho', Số chuyên đề: Môi trường và Biến đổi khí hậu 2017, 1, 64-70.

9. Thục, T.; Tường, L.N.; Thắng, N.V.; Thái, T.H. Thích ứng với biến đổi khí hậu và phát triển bền vững. Báo cáo hội thảo Tham vấn quốc gia về chương trình mục tiêu quốc gia ứng phó với biến đổi khí hậu và nước biển dâng, 2008, 4-12.

10. Thục, T.; Hương, T.T.T.; Thắng, N.V.; Nhuận, M.T.; Trí, L.Q.; Thành, L.Đ.; Hương, H.T.L.; Sơn, V.T.; Thuận, N.T.H. và Tường, L.N. Báo cáo đặc biệt của Việt Nam về Quản lý rủi ro thiên tai và hiện tượng cực đoan nhằm thúc đẩy thích ứng với biến đổi khí hậu. NXB Tài nguyên-Môi trường và Bản đồ Việt Nam, Hà Nội, Việt Nam, 2015.

11. Bộ Tài nguyên và Môi trường. Thông báo Quốc gia lần thứ ba của Việt Nam cho Công ước khung của Liên Hợp Quốc về biến đổi khí hậu, 2018.

12. Nam, L.H.; Tín, N.V.; Toàn, H.C.; Hoàng, T.T.; Long, P.T. Đánh giá xu thế và xây dựng kịch bản biến đổi khí hậu cho tỉnh Bình Phước. Tạp chí Khí tượng Thủy văn 2020, 717, 32-43. https://doi.org/10.36335/VNJHM.2020(717).32-43. 
13. Tuân, H.M.; Tuấn, N.M.; Huyền, K.T.T.; Long, N.H. Tác động của biến đổi khí hậu đến nông nghiệp và các sáng kiến thích ứng với biển đổi khí hậu tại huyện Văn Bàn, tỉnh Lào Cai. Tạp chí Khoa học và Công nghệ - Đại học Thái Nguyên 2019, 201, $115-120$.

14. Ngọc, N.B.; Ngũ̃, N.H.; Đức, T.T. Đánh giá các loại hình sử dụng đất nông nghiệp thích ứng với biến đổi khí hậu ở huyện Quảng Điền, tỉnh Thừa Thiên Huế. Tạp chí Khoa học Đại học Huế: Nông nghiệp và Phát triển nông thôn 2018, 27(3B), 83-95. https://doi.org/10.26459.

15. Vũ, P.T.; Minh, V.Q.; Huy, V.T.; Nguyện, P.C. Tác động của mặn và ngập theo kịch bản biến đổi khí hậu đến tiềm năng thích nghi đất đai vùng ven biển đồng bằng sông Cửu Long. Tạp chí Khoa học Trương Đại học Cần Tho; Nông nghiệp 2016, 4, 7183. https://doi.org/10.22144/ctu.jsi.2016.105.

16. Hương, T.T.G.; Vòng, N.T.; Tăng, B.M. Bố trí sử dụng đất của tỉnh Nam Định để thích ứng với biến đồi khí hậu. Tạp chi Khoa học và Phát triển 2015, 13(6), 921930.

\title{
Assessment of climate change impacts on land use and some climate change adaptation measures in Binh Phuoc province
}

\author{
Le Hoai Nam ${ }^{1}$, Nguyen Van Tin ${ }^{3}$, Ho Cong Toan², Tran Tuan Hoang², Pham Thanh \\ Long $^{2}$ \\ ${ }^{1}$ Southern Center for Enviromental Monitoring; lhnammt@gmail.com; \\ ${ }^{2}$ Sub-Institute of Hydrometeogology and Climate change; hoangkttv@gmail.com; \\ longpham.sihymete@gmail.com; hocongtoanhdh@gmail.com; \\ ${ }^{3}$ Ho Chi Minh University of Natural Resources and Enviroment; tin.sihymete@gmail.com;
}

\begin{abstract}
The study gives the results of analysis and assessment of the impact of climate change (CC) on the land use sector in Binh Phuoc province based on the evaluation indexes according to the results of the climate model, the flooding model. On that basis, the study gave results on the level of impacts and their impact assessment on land use (land use) in Binh Phuoc province, specifically: land use in Dong Xoai city suffered the lowest impact level from 0.54-0.55; Bu Dop district is affected by climate change on a high level of land use, with impact indexes from 0.60-0.66 under some scenarios. Other districts and towns in Binh Phuoc province have medium to high impact range with impact indexes of 0.540.60 . The article has outlined the impact of climate change, at the same time proposing some solutions to adapt to climate change, these research results will contribute to providing information for Binh Phuoc province, serving the re-planning of malnutrition. reasonable way in the context of climate change.
\end{abstract}

Keywords: Impact; Climate change; Land use; Adaptation. 